\title{
Dietary resveratrol does not delay engraftment, sensitize to vincristine or inhibit growth of high-risk acute lymphoblastic leukemia cells in NOD/SCID mice
}

\author{
SUSAN J. ZUNINO ${ }^{1}$, DAVID H. STORMS ${ }^{1}$, JOHN W. NEWMAN ${ }^{1}$, THERESA L. PEDERSEN ${ }^{1}$, \\ CARL L. KEEN ${ }^{2}$ and JONATHAN M. DUCORE ${ }^{3}$

\begin{abstract}
${ }^{1}$ United States Department of Agriculture, Agricultural Research Service, Western Human Nutrition Research Center, Davis, CA; ${ }^{2}$ Department of Nutrition, University of California Davis, Davis, CA 95616; ${ }^{3}$ Department of Pediatrics, Section of Hematology/Oncology, University of California School of Medicine, Sacramento, CA 95817, USA
\end{abstract}

Received July 18, 2012; Accepted September 11, 2012

DOI: $10.3892 /$ ijo.2012.1650

\begin{abstract}
Acute lymphoblastic leukemia (ALL) with translocation $\mathrm{t}(4 ; 11)$ is a high-risk leukemia found in $60-85 \%$ of infants with ALL and is often refractory to conventional chemotherapeutics after relapse. To evaluate the efficacy of dietary resveratrol in vivo, 5-week-old NOD.CB17-Prkdcscid/J mice were fed a control diet or a diet containing $0.2 \% \mathrm{w} / \mathrm{w}$ resveratrol. After 3 weeks of dietary treatment, mice were engrafted with the human $\mathrm{t}(4 ; 11)$ ALL line SEM by tail vein injection. Engraftment was monitored by evaluating the presence of human CD19+ cells in peripheral blood using flow cytometry. Relative to control diet, dietary resveratrol did not delay the engraftment of the leukemia cells. To determine if dietary resveratrol could increase efficacy of a chemotherapeutic agent, vincristine was injected intraperitoneally into leukemic mice fed the control or supplemented diet. Survival curves and monitoring the percentage of human leukemia cells in peripheral blood showed that resveratrol did not inhibit leukemia cell growth or influence the activity of vincristine. Mass spectrometric analysis of mouse serum revealed that the majority of resveratrol was present as glucuronidated and sulfated metabolites. These data do not support the concept that dietary resveratrol has potential as a preventative agent against the growth of high-risk t(4;11) ALL.
\end{abstract}

\section{Introduction}

Resveratrol (3,5,4'-trihydroxy-trans-stilbene) is a plant polyphenol that is present in grapes, red wine, blueberries, mulberries, and cranberries (1). In vitro studies have shown that resveratrol can inhibit proliferation and induce apoptosis in different types

Correspondence to: Dr Susan J. Zunino, USDA, ARS, Western Human Nutrition Research Center, 430 West Health Sciences Drive, Davis, CA 95616, USA

E-mail: susan.zunino@ars.usda.gov

Key words: acute lymphoblastic leukemia, dietary resveratrol, NOD/ SCID mice of cancer cells (1). In vivo, resveratrol has been reported to be an effective agent against breast, esophageal, lung, and colon cancers in animal models (2-6). Furthermore, resveratrol has been reported to sensitize neuroblastoma, glioblastoma, breast carcinoma, prostate carcinoma, leukemia, and pancreatic carcinoma cells to the actions of multiple traditional chemotherapeutic agents in vitro (7). At a molecular level, resveratrol has been reported to act as an antioxidant, inhibit transcription factor and kinase activation required for cell growth, and inhibit cell cycle progression (1,8-10).

High-risk acute lymphoblastic leukemia (ALL) with chromosomal translocation $\mathrm{t}(4 ; 11)$ has a poor prognosis for patients. A significant problem that limits survival of patients with $t(4 ; 11)$ ALL is the relapse of chemotherapy-resistant leukemia $(11,12)$. The $t(4 ; 11)$ ALL is a pre-B cell leukemia found in $60-85 \%$ of infants with ALL. Several cell lines have been established from patients with $t(4 ; 11)$ ALL and these lines have been used in vitro to evaluate novel therapeutic agents (13-15). The nonobese diabetic $x$ severe combined immunodeficient (NOD/ SCID) mouse model has been useful for evaluating different chemotherapeutic agents against leukemia (16-19). The SCID background has an absence of $\mathrm{T}$ and $\mathrm{B}$ lymphocyte populations and the NOD background provides reduced natural killer lymphocyte activity and absence of circulating complement that increase engraftment efficiency of human cells. The NOD/ SCID mouse model for leukemia mimics the human disease by homing to, and engrafting in, the bone marrow, spleen, and liver. The engraftment in organ sites correlates well with the presence of leukemia cells in the peripheral blood (20).

We have reported that resveratrol, as well as several other plant-derived polyphenols, such as carnosol, curcumin, and quercetin, are effective in vitro in inducing apoptotic cell death in $\mathrm{t}(4 ; 11)$ and other ALL-derived cell lines (21-23). While resveratrol has been shown to act by stimulating CD95 ${ }^{-}$signaling in some cancer cells, the induction of apoptosis in the $t(4 ; 11)$ ALL lines by resveratrol occurred exclusively by disruption of mitochondrial homeostasis (21). These in vitro studies supported the concept that resveratrol has potential as a preventative agent against high-risk leukemia in vivo. In the current study, we determined whether dietary resveratrol prevented the engraft- 
ment and growth of the $t(4 ; 11)$ ALL cells in NOD/SCID mice. In addition, we tested the hypothesis that it could increase the efficacy of the chemotherapeutic agent vincristine; a standard chemotherapeutic agent used to treat this type of leukemia (24).

\section{Materials and methods}

Cells and reagents. SEM is a cell line that was established from a patient diagnosed with high-risk pre-B ALL containing the chromosomal translocation $\mathrm{t}(4 ; 11)(\mathrm{q} 21 ; \mathrm{q} 23)$ (13). The cells were grown at $37^{\circ} \mathrm{C}, 5 \% \mathrm{CO}_{2}$ in RPMI-1640 (Invitrogen, Carlsbad, CA) that was supplemented with $10 \%$ fetal bovine serum (Sigma, St. Louis, MO), $50 \mathrm{IU} / \mathrm{ml}$ penicillin, $50 \mathrm{mg} / \mathrm{l}$ streptomycin, $0.25 \mathrm{mg} / \mathrm{l}$ amphotericin $\mathrm{B}, 1 \mathrm{mmol} / \mathrm{l}$ sodium pyruvate, and $2 \mathrm{mmol} / \mathrm{l} \mathrm{L-glutamine} \mathrm{(Invitrogen).} \mathrm{For} \mathrm{injec-}$ tion into mice, SEM cells were collected and washed 2 times in Dulbecco's PBS without $\mathrm{Ca}^{2+}$ or $\mathrm{Mg}^{+}$(Sigma). The cells were resuspended in PBS at a final concentration of $50 \times 10^{6}$ cells $/ \mathrm{ml}$.

Vincristine sulfate (Sigma) was dissolved in PBS and stored at $-20^{\circ} \mathrm{C}$. To monitor leukemia burden in the blood, peripheral blood leukocytes were stained with phycoerythrincyanin 7 (PE-Cy7)-conjugated anti-human CD19 and allophycocyanin-Cy7 (APC-Cy7) conjugated anti-mouse CD45 (Becton-Dickinson, San Jose, CA). Trans-resveratrol, tetra-deuterated trans-resveratrol (resveratrol-d4), resveratrol3-O-D-glucuronide, resveratrol-4'-O-D-glucuronide, and resveratrol-3-O-sulfate, and 1-cyclohexyluriedo-3-dodecanoic acid (CUDA) were purchased from Cayman Chemical Co. (Ann Arbor, MI). Sulfatase from Aerobacter aerogenes, $\beta$-glucuronidase (Type IX-A) from Escherichia coli, formic acid, glycerol, potassium 4-nitrophenyl sulfate, and 4-nitrophenyl $\beta$-D-glucuronide were obtained from Sigma. Ammonium hydroxide and LC/MS grades of methanol, acetonitrile, and water were purchased from Fisher Scientific (Fair Lawn, NJ). Normal mouse serum was obtained from United States Biological (Swampscott, MA).

Diets. Resveratrol (>98\% pure) was purchased in bulk from Cayman Chemical Co. Rodent Diet 7013 (Harlan Teklad, Madison, WI), a commercial NIH-31 modified diet, was used as the base diet because it is similar in composition to the diet used by Jackson Laboratory for maintenance of the NOD. CB17-Prkdcscid/J mouse strain. The diets used in the current study were prepared by Harlan Teklad. Diet 1 was the base diet (control) and diet 2 was the base diet containing $0.2 \%$ $\mathrm{w} / \mathrm{w}$ resveratrol. A dietary concentration of $0.2 \% \mathrm{w} / \mathrm{w}$ resveratrol is equivalent to approximately $300 \mathrm{mg} / \mathrm{kg}$ body weight/ day assuming a $20 \mathrm{-g}$ mouse and consumption of $3 \mathrm{~g}$ of food/ day. This dietary concentration was chosen to both minimize the risk for resveratrol-induced renal toxicity (25), and ensure that reasonable blood concentrations of resveratrol would reach the leukemia cells at engraftment sites. For the addition of the supplement, Rodent Diet 7013 was ground, the resveratrol was added, and the diet was repelleted. The control diet was also ground and repelleted so that the consistency of the food for each group was similar. The diets were $\gamma$-irradiated to sterilize and packaged in $2 \mathrm{~kg}$ vacuum sealed bags to reduce exposure to air. Diets were stored at $-20^{\circ} \mathrm{C}$ until use and fresh food was given to the mice weekly.
Mice. Experimental procedures using mice were approved by the University of California, Davis Institutional Animal Care and Use Committee. Female NOD.CB17-Prkdcscid/J mice (5 weeks of age) were purchased from the Jackson Laboratory (Bar Harbor, ME, common name NOD/SCID). Upon arrival, the mice were randomly sorted into 2 groups ( $n=16$ per group) and given the control diet or diet containing $0.2 \% \mathrm{w} / \mathrm{w}$ resveratrol. Mice were given sterilized food and water ad libitum. Mice were housed under $12 \mathrm{~h}$ light-dark cycle, pathogen-free, temperature controlled conditions in ventilator racks at a University of California, Davis vivarium. Mice were weighed weekly. Weighing of mice and injections of leukemia cells or chemotherapeutic agent were performed in a biosafety cabinet to maintain pathogen-free conditions. Additions of food and water, and cage changes were performed in a laminar flow change-out cabinet. Mice were euthanized by carbon dioxide asphyxiation.

Leukemia cell engraftment. After receiving the diets for 3 weeks, each mouse was injected with $5 \times 10^{6}$ SEM cells (100 $\mu \mathrm{l}$ volume) through the tail vein. Approximately 2 weeks after injecting the leukemia cells, blood was collected from the tail artery of each mouse once per week using heparinized Microvette tubes (Sarstedt, Newton, NC). Blood from each mouse (approximately $50 \mu \mathrm{l}$ ) was transferred to a separate $1.5 \mathrm{ml}$ microfuge tube and the red blood cells were lysed using PharmLyse (Becton-Dickinson) according to the manufacturer's suggestions. The resulting peripheral blood leukocytes (PBLs) were stained with PE-Cy7 conjugated anti-human CD19 and APC-Cy7 conjugated anti-mouse CD45. The cells were incubated with antibodies at room temperature for $20 \mathrm{~min}$, washed in PBS containing 0.1\% BSA and $7 \mathrm{mmol} / \mathrm{l}$ sodium azide (Sigma), and then fixed in 1\% paraformaldehyde (Sigma) before analysis on a FACSCanto ${ }^{\mathrm{TM}}$ fluorescence-activated cell sorter (FACS) using FACSDiva ${ }^{\mathrm{TM}}$ software (Becton-Dickinson). Analysis of leukocytes was performed using appropriate scatter gates to exclude cellular debris and aggregated cells. The negative control was PBLs isolated from NOD/SCID mice that had not been injected with leukemia cells. The positive control was made by spiking an aliquot of PBLs (isolated from mice without leukemia) with SEM cells. Both the negative and positive control cells were stained with PE-Cy7 conjugated anti-human CD19 and APC-Cy 7 conjugated anti-mouse CD45 and used to set the gates for human $\mathrm{CD} 19^{+}$cells. Thirty thousand events were collected for each sample. Positive engraftment was defined as $1 \%$ or greater human $\mathrm{CD} 19^{+}$cells present in the murine PBL population $(18,19)$.

Treatment with vincristine. All mice were injected intraperitoneally (i.p.) with vincristine at a concentration of $0.5 \mathrm{mg} / \mathrm{kg}$ body weight 3 times per week beginning approximately 4.5 weeks after injection of leukemia cells (26). The total volume for each injection of vincristine was approximately $100 \mu \mathrm{l}$ and was adjusted weekly according to the body weight of each mouse. All animals were fed the control or resveratrol diets during the chemotherapeutic treatment, and the percentage of human leukemia cells was monitored by flow cytometry as described above.

Liquid chromatography $(L C)$ - tandem mass spectrometry (MS) analysis. Serum samples from NOD/SCID mice $(\mathrm{n}=5)$ 


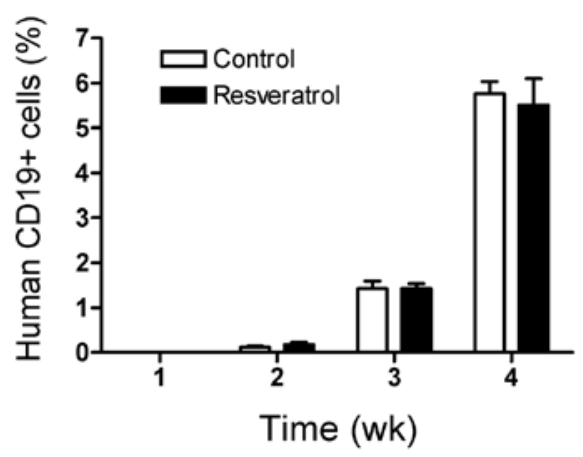

Figure 1. Dietary resveratrol did not inhibit engraftment of $t(4 ; 11)$ ALL cells. Mice were fed control or resveratrol supplemented diets ( $n=16$ per group) for 3 weeks prior to injection of $5 \times 10^{6} \mathrm{SEM}$ leukemia cells into the tail vein. Mice were monitored for engraftment of the leukemia by measuring the percentage of human $\mathrm{CD}^{+} 9^{+}$cells in the mouse peripheral blood leukocyte (PBL) population by flow cytometry. Engraftment was defined as $1 \%$ or greater human $\mathrm{CD}_{1}{ }^{+}$cells present in the murine PBL population. The graph represents the time after injection of the leukemia cell. The bars represent means \pm SEM. No difference in the percentage of $\mathrm{CD} 19^{+}$cells was observed between the dietary groups $(\mathrm{P}=0.78)$.

were prepared at the time of euthanization and stored at $-70^{\circ} \mathrm{C}$ until use. Serum from each mouse was separated into three $25 \mu \mathrm{l}$ aliquots for enzymatic digestion using a mock control (no enzyme), $\beta$-glucuronidase, or sulfatase. The serum samples were processed and analyzed as previously described (27).

Statistical analysis. Statistical analyses were performed with GraphPad software (GraphPad Software, Inc., San Diego, CA) and data are displayed as arithmetic means \pm SEM. Event free survival (EFS) was used for comparisons between the treatment groups, and was defined by overt clinical illness requiring euthanization, that included greater than $20 \%$ weight loss, lethargy, severe weakness, or inability to reach food or water for $24 \mathrm{~h}$. The EFS was calculated beginning with the day of injection of the leukemia cells. Kaplan-Meier survival curves were used to determine differences in EFS by log-rank test. Differences in the body weights and percentage of $\mathrm{CD} 19^{+}$cells between the dietary groups were analyzed by 2-way ANOVA with Bonferroni posttests. The confidence interval for significant differences was set at $95 \%$.

\section{Results}

Dietary resveratrol does not inhibit engraftment of leukemia. Mice were fed specialized diets for 3 weeks prior to injecting the leukemia cells to determine if dietary resveratrol delayed engraftment. Engraftment of SEM leukemia cells was $100 \%$ in both control and resveratrol fed mice. The rate of engraftment as measured by the percentage of SEM leukemia cells in the PBL population in control and resveratrol fed mice was similar over a 4-week period after injection of the leukemia cells and prior to treatment with vincristine (Fig. 1, $\mathrm{P}=0.78$ ).

Dietary resveratrol does not sensitize the leukemia cells to vincristine. Mice were treated with vincristine at week 4 when the mean percentage of human leukemia cells in the mouse PBL population reached approximately $5.8 \pm 0.3 \%$ for the control group and $5.5 \pm 0.6 \%$ in the resveratrol fed group (Fig. 2). Mice in
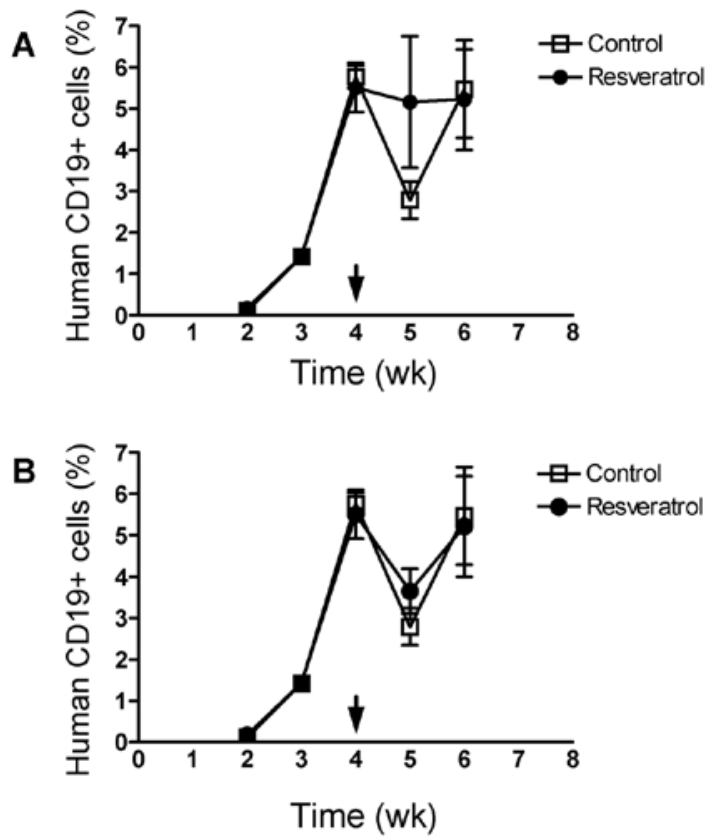

Figure 2. Dietary resveratrol did not sensitize $t(4 ; 11)$ ALL cells to vincristine treatment. Mice were fed control or resveratrol supplemented diets $(n=16$ per group) for 3 weeks prior to injection of $5 \times 10^{6}$ SEM leukemia cells into the tail vein. Mice were monitored for engraftment of the leukemia by flow cytometry beginning at 2 weeks after injection of the leukemia cells as described in Fig. 1. Arrows indicate the initiation of vincristine treatment at a dose of $0.5 \mathrm{mg} / \mathrm{kg}$ body weight 3 times per week. (A), Represents data for all mice in each group. One mouse in the resveratrol fed group had a leukemia burden of approximately $10 \%$ and showed a delayed response to the vincristine treatment, resulting in the large standard error at week 5. (B), Represents data shown in (A) minus the highly engrafted mouse, indicating that vincristine was similarly effective in reducing the leukemic burden in both groups. Data are presented as mean \pm SEM. No differences in the percentage of CD19 ${ }^{+}$cells between the dietary groups was observed (2-way ANOVA, $\mathrm{P}=0.39$ using all mice in each group).

both feeding groups initially responded to the vincristine treatment, resulting in a temporary decrease in leukemia burden. One mouse in the resveratrol fed group had a leukemia burden of approximately $10 \%$ in the peripheral blood and showed a delayed response to the vincristine treatment, resulting in the large standard error at week 5 (Fig. 2A). Removal of this mouse from the data analysis showed that vincristine treatment produced a similar reduction in the leukemia burden between the two dietary groups (Fig. 2B). Overall, there was no difference in the percentage of human leukemia cells in the mouse PBL population between the mice fed the control or resveratrol diets at weeks 5 and 6 after vincristine treatment $(\mathrm{P}=0.39$, Fig. 2A, all data). After 2 weeks of treatment with vincristine, the leukemia burden began to increase and the mice became clinically ill.

Dietary resveratrol does not increase survival of leukemic mice. Mice were fed the control or resveratrol supplemented diets 3 weeks before injection of leukemia cells and throughout the experimental period. Survival was similar between the control and resveratrol supplemented mice (Fig. 3, $\mathrm{P}=0.74$ ). The mice succumbed to the disease rapidly about 6 weeks after injection of the leukemia cells, and 2 weeks after treatment with vincristine. Mean body weights were similar between the 


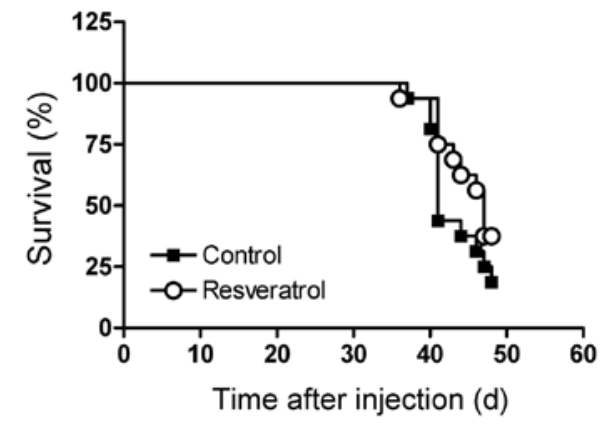

Figure 3. Dietary resveratrol did not increase survival of the leukemic mice compared to the control diet. The mice were fed control or resveratrol supplemented diets 3 weeks prior to injection of the leukemia cells into the tail vein ( $\mathrm{n}=16$ per group). Treatment with vincristine was initiated at approximately 28-30 days after injection of the leukemia cells. The mice were euthanized when they became clinically ill. Differences in survival after treatment began were determined by log-rank test. No difference in survival between the dietary groups was observed $(\mathrm{P}=0.74)$.

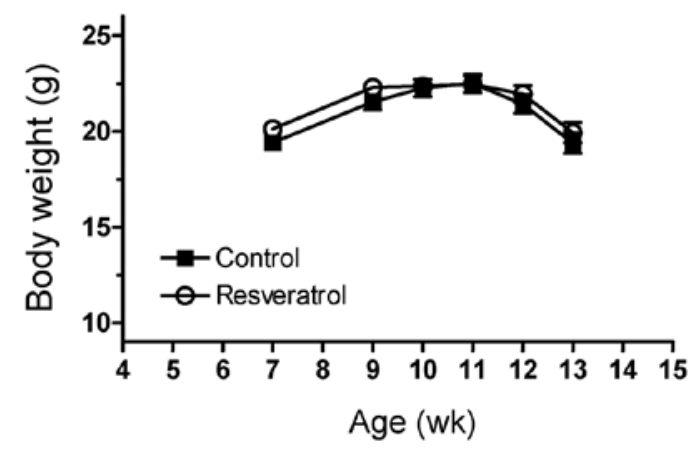

Figure 4. Body weights of the mice fed control or resveratrol supplemented diets were not different. Body weights of the mice were measured weekly. The mice were fed the control or resveratrol diets beginning at the age of 5 weeks and maintained on the diets throughout the experimental period. SEM leukemia cells were injected at the age of 8 weeks. Vincristine treatment was begun at about 12 weeks of age. The data represent means \pm SEM. No differences in body weight were observed between the 2 dietary groups $(\mathrm{P}=0.09)$.

control and resveratrol supplemented mice before and after injection of the leukemia cells at 8 weeks of age (Fig. 4, P=0.09). Body weight loss was evident by $4-5$ weeks after the injection of leukemia cells, and the mice continued to lose weight during the vincristine treatment.

Dietary resveratrol was extensively metabolized to glucuronides and sulfates. Due to the lack of anti-leukemia activity of resveratrol, the metabolism of resveratrol was evaluated by LC-MS in a subpopulation of surviving mice that were showing signs of clinical illness, but were still mobile and able to reach food $(n=5)$. The mice were euthanized and the serum was either mock digested or digested with $\beta$-glucuronidase or sulfatase. The resulting increases in resveratrol aglycone after enzymatic digestion were used to determine the concentrations of glucuronidated and sulfated metabolites. Incubation of serum with either $\beta$-glucuronidase or sulfatase increased the peak intensities of extractable resveratrol compared to the mock digested serum (Fig. 5A). The majority of the total resveratrol in the serum was present as metabolites. The mean percentage of resveratrol aglycone was $16 \pm 6 \%$, whereas $57 \pm 9 \%$ and $27 \pm 6 \%$ of resveratrol was
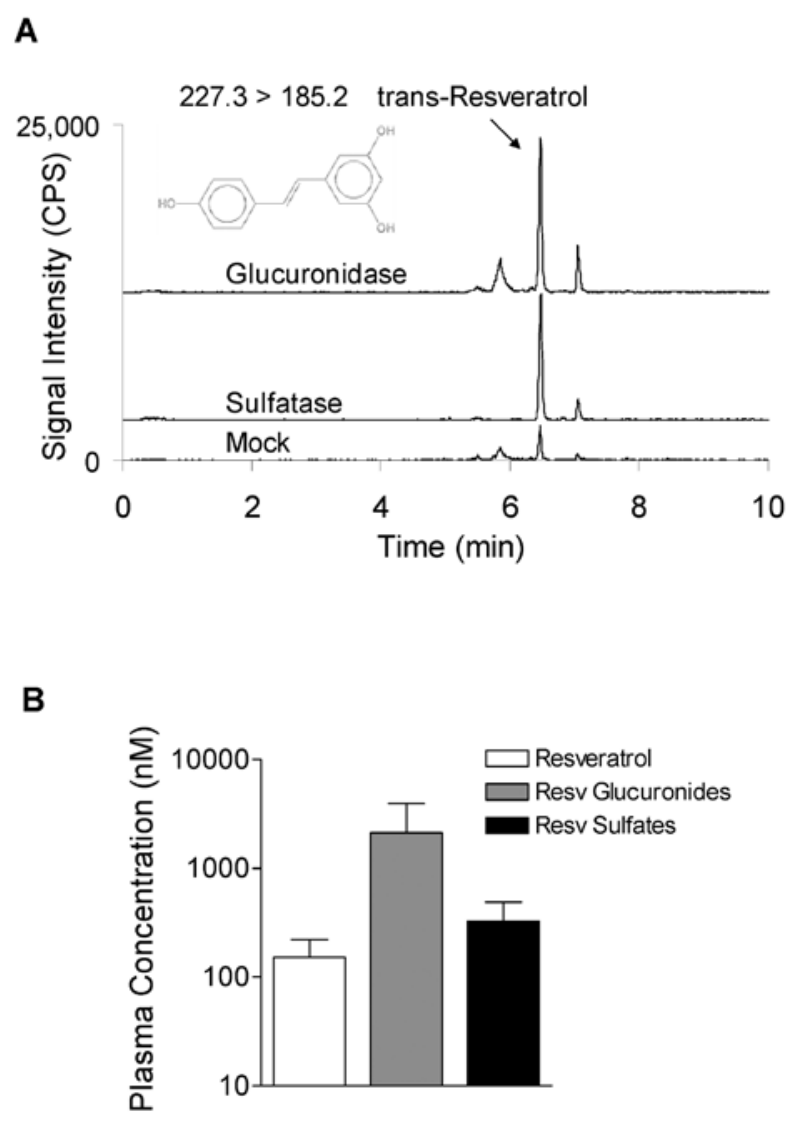

Figure 5. Dietary resveratrol was metabolized to glucuronidated and sulfated forms in leukemic mice. (A), Representative UPLC-MS/MS chromatograms of resveratrol isolated from serum collected from leukemic mice at the time of euthanization shows the metabolic profile of resveratrol after digestion with buffer (mock), $\beta$-glucuronidase, or sulfatase. Signal intensities for each mass transition are equivalent in the three panels. Deconjugation reactions increased peak areas of resveratrol relative to mock digestions, demonstrating the generation of glucuronide and sulfate conjugates in vivo. (B), Mean plasma concentrations of resveratrol aglycone and metabolites from 5 mice. The percentage of distribution of aglycone: glucuronides: sulfates was 16:57:27. The data represent means \pm SEM.

present as monoglucuronides and monosulfates, respectively (Fig. 5B). The 4-nitrophenyl glucuronide and sulfate conjugates (digestion controls) showed greater than 99\% deconjugation efficiency. Deuterated resveratrol (surrogate) recoveries were $45 \pm 6 \%, 50 \pm 2 \%$, and $62 \pm 3 \%$ for the mock, $\beta$-glucuronidase and sulfatase digestions, respectively.

\section{Discussion}

In human feeding studies, resveratrol has been used at levels up to $5 \mathrm{~g} /$ day, with some adverse results, including diarrhea, nausea, and abdominal pain, being reported at doses ranging from 2.5 to $5 \mathrm{~g}$ /day $(28,29)$. In a $50-70 \mathrm{~kg}$ adult, the dose of $5 \mathrm{~g} /$ day corresponds to $71-100 \mathrm{mg} / \mathrm{kg}$ body weight/day in humans. Due to the adverse responses in humans, it has been suggested that levels of dietary resveratrol for humans should not exceed $1 \mathrm{~g}$ /day. Toxicity studies have been performed in rats with oral administration of 100,300 , and $3000 \mathrm{mg} / \mathrm{kg}$ body weight/day and resveratrol was reported to have renal toxicity at $3000 \mathrm{mg} / \mathrm{kg}$ body weight (25). In the present study with mice, we chose a dietary concentration of $0.2 \% \mathrm{w} / \mathrm{w}$ resveratrol that 
is approximately $300 \mathrm{mg} / \mathrm{kg}$ body weight/day assuming a 20mouse and consumption of $3 \mathrm{~g}$ of food/day diet. This dietary concentration was used to reduce renal toxicity in the mice, while ensuring there was a high potential of the resveratrol to reach the organs and tissues that harbored the leukemia cells. Despite the high amount $(0.2 \%$ of the diet) of resveratrol given in the current study, there was no indication that its inclusion in the diet inhibited the engraftment or growth of high-risk $t(4 ; 11)$ leukemia in NOD/SCID mice.

Studies have been performed in both humans and experimental animals to determine the tissue distribution, excretion rates, and general bioavailability of resveratrol after its oral administration. In humans, after $25 \mathrm{mg}$ of ${ }^{14} \mathrm{C}$-labelled resveratrol was given as a single oral dose, the concentration of resveratrol peaked at approximately $500 \mathrm{ng} / \mathrm{ml}$ in the plasma $(2 \mu \mathrm{mol} / \mathrm{l})$ at $1 \mathrm{~h}$, with a second peak of approximately $300 \mathrm{ng} / \mathrm{ml}$ $(1.3 \mu \mathrm{mol} / \mathrm{l})$ at $6 \mathrm{~h}(30)$. In these experiments, there was at least $70 \%$ absorption of resveratrol and most of the oral dose was recovered in the urine. Although the plasma levels were low with the single oral dose of $25 \mathrm{mg}$, absorption was rapid and efficient and the plasma half-life of resveratrol and metabolites was calculated at $9.2 \mathrm{~h}$. The major forms of resveratrol observed in this study were sulfate and glucuronide conjugates. More recently, humans given daily doses of $0.5,1,2.5$, or $5 \mathrm{~g}$ for 29 days showed maximal plasma concentrations of the resveratrol aglycone at $0.19,0.62,1.45$, and $4.24 \mu \mathrm{mol} / 1$, respectively (28). However, the time of maximal plasma concentration of resveratrol aglycone in the human study was approximately $1 \mathrm{~h}$ and the majority of the resveratrol had been converted to the resveratrol-4'-O-glucuronide, resveratrol-3-O-glucuronide, and resveratrol-3-O-sulfate.

The tissue distribution of orally administered resveratrol has been reported in animal models. In mice, a single oral dose of ${ }^{14} \mathrm{C}$-labelled resveratrol $(5 \mathrm{mg} / \mathrm{kg}$ body weight) showed distribution in the duodenum, colon, liver, kidney, lung, spleen, heart, brain, and testis by $3 \mathrm{~h}$, with the highest content in the duodenum (31). Longer term experiments utilizing rats showed the presence of resveratrol metabolites in the plasma after an 8 -week feeding of $300 \mathrm{mg}$ resveratrol $/ \mathrm{kg}$ body weight per day (32). The plasma, liver, kidney, urine, and feces contained mainly the sulfated and glucuronidated forms of resveratrol in these rats. By the end of the 8-week feeding study, the concentrations of the different resveratrol conjugates in the plasma ranged from 0.37 to $7.46 \mathrm{mg} / 1$ (1.6-32.7 $\mu \mathrm{mol} / \mathrm{l})$. In the present study, only nmol/1 levels of resveratrol aglycone were detected, but approximately $2 \mu \mathrm{mol} / 1$ glucuronide metabolites were present in the serum of leukemic NOD/SCID mice. Taken together, the SEM leukemia cells in the target organs (spleen, liver, and bone marrow) would have been mostly exposed to resveratrol metabolites rather than the resveratrol aglycone. Further investigations will be required to evaluate the apoptotic activities of resveratrol metabolites against leukemia cells. However, our data suggest that the leukemia cells were not exposed to high enough levels of resveratrol aglycone and/or metabolites to induce leukemia cell death.

The majority of in vitro studies on resveratrol focused on the study of the putative anti-cancer activity of this nutrient have been conducted using nonphysiological $\mu \mathrm{mol} / \mathrm{l}$ concentrations of the resveratrol aglycone. We submit that these types of in vitro experiments have limited value to elucidate the chemopreventive or therapeutic potential of resveratrol against leukemia in vivo. However, we note that resveratrol has been reported to have some efficacy in decreasing tumor burden and metastatic potential of a number of different cancers in rodent models (33). Resveratrol has been reported to inhibit metastasis of lung cancer and melanoma after intraperitoneal injection, and colon carcinoma metastasis after oral administration (34-36). Resveratrol has been reported to sensitize a number of cancers to chemotherapeutic agents in vitro and the mechanisms of this sensitization include down-regulation of multi-drug resistant protein expression, modulating the expression of cell survival proteins such as Bcl-2, down-regulating the transcription factor $\mathrm{NF}-\kappa \mathrm{B}$, and cell cycle arrest (7). Reversal of doxorubicin resistance in acute myeloid leukemia in vitro was reported to be mediated by down-regulation of the multi-drug resistant protein MRP-1, but only at a nonphysiological dose of $50 \mu \mathrm{mol} / 1$ (37). Limited data exist on the chemosensitizing effects of resveratrol in vivo. It was recently reported that resveratrol administered daily by gavage (at a dose of $40 \mathrm{mg} / \mathrm{kg}$ body weight) for 35 days significantly reduced the size of ectopic pancreatic tumors in nude mice, and that it potentiated the effects of gemcitabine in this model of pancreatic cancer (38). These experiments suggest that resveratrol may have potential as a chemopreventive agent depending upon the type of cancer and/or route of administration, and may be beneficial in the prevention of metastasis.

High-risk $\mathrm{t}(4 ; 11)$ ALL is an aggressive leukemia that has a poor prognosis due to development of chemotherapy resistant cells. The t $(4 ; 11)$ ALL line SEM was established from a relapsed patient that had undergone chemotherapy (13). Engraftment of these cells in NOD/SCID mice was achieved rapidly within 2-3 weeks after injection of the leukemia cells. In vitro, the SEM cells are responsive to vincristine-induced apoptosis, but upon engraftment into NOD/SCID mice and treatment with vincristine, SEM cells revert to a vincristineresistant phenotype due in part by an increased expression of the multi-drug resistant protein P-glycoprotein (26). Dietary resveratrol did not sensitize these leukemia cells to vincristine treatment, nor did this dietary nutrient inhibit the rapid engraftment and growth of SEM cells in the NOD/SCID mice. In summary, while dietary resveratrol may have potential as a chemopreventive agent against some cancers, the results presented in the current study suggest that this agent has minimal value with respect to the treatment or prevention of high-risk $\mathrm{t}(4 ; 11)$ ALL in vivo.

\section{Acknowledgements}

This work was supported by an award from National Institutes of Health, National Cancer Institute, award no. 1R21CA122117-01. The content is solely the responsibility of the authors and does not necessarily represent the official views of the National Institutes of Health. No conflicts of interest are present for any of the authors. USDA is an equal opportunity provider and employer.

\section{References}

1. Aggarwal BB, Bhardwaj A, Aggarwal RS, Seeram NP, Shishodia S, et al: Role of resveratrol in prevention and therapy of cancer: preclinical and clinical studies. Anticancer Res 24: 2783-2840, 2004. 
2. Banerjee S, Bueso-Ramos C and Aggarwal BB: Suppression of 7,12-dimethylbenz(a)anthracene-induced mammary carcinogenesis in rats by resveratrol: role of nuclear factor- $\kappa \mathrm{B}$, cyclooxygenase 2, and matrix metalloproteinase 9. Cancer Res 62: 4945-4954, 2002.

3. LiZG,Hong T, Shimada Y,Komoto I,Kawabe A, et al: Suppression of N-nitrosomethylbenzylamine (NMBA)-induced esophageal tumorigenesis in F344 rats by resveratrol. Carcinogenesis 23 1531-1536, 2002.

4. Lee EO, Lee HJ, Hwang HS, Ahn KS, Chae C, et al: Potent inhibition of Lewis lung cancer growth by heyneanol A from the roots of Vitis amurensis through apoptotic and anti-angiogenic activities. Carcinogenesis 27: 2059-2069, 2006.

5. Liu HS, Pan CE, Yang W and Liu XM: Antitumor and immunomodulatory activity of resveratrol on experimentally implanted tumor of $\mathrm{H} 22$ in Balb/c mice. World J Gastroenterol 9: 1474-1476, 2003.

6. Tessitore L, Davit A, Sarotto I and Caderni G: Resveratrol depresses the growth of colorectal aberrant crypt foci by affecting bax and p21(CIP) expression. Carcinogenesis 21: 1619-1622,2000.

7. Gupta SC, Kannappan R, Reuter S, Kim JH and Aggarwal BB Chemosensitization of tumors by resveratrol. Ann NY Acad Sci 1215: 150-160, 2011.

8. Colin D, Limagne E, Jeanningros S, Jacquel A, Lizard G, et al: Endocytosis of resveratrol via lipid rafts and activation of downstream signaling pathways in cancer cells. Cancer Prev Res 4: 1095-1106, 2011.

9. Li G, He S, Chang L, Lu H, Zhang H, et al: GADD $45 \alpha$ and annexin A1 are involved in the apoptosis of HL-60 induced by resveratrol. Phytomedicine 18: 704-709, 2011.

10. Kartal M, Saydam G, Sahin F and Baran Y: Resveratrol triggers apoptosis through ceramide metabolizing genes in human K562 chronic myeloid leukemia cells. Nutr Cancer 63: 637-644, 2011.

11. Faderl S, Kantarjian HM, Talpaz M and Estrov Z: Clinical significance of cytogenetic abnormalities in adult acute lymphoblastic leukemia. Blood 91: 3995-4019, 1998

12. Greaves MF and Wiemels J: Origins of chromosome translocations in childhood leukaemia. Nat Rev 3: 1-11, 2003.

13. Greil J, Gramatzki M, Burger R, Marschalek R, Peltner M, et al: The acute lymphoblastic leukaemia cell line SEM with $\mathrm{t}(4 ; 11)$ chromosomal rearrangement is biphenotypic and responsive to interleukin-7. Br J Haematol 86: 275-283, 1994.

14. Stong RC, Korsmeyer SJ, Parkin JL, Arthur DC and Kersey JH: Human acute leukemia cell line with the $t(4 ; 11)$ chromosomal rearrangement exhibits $B$ lineage and monocytic characteristics. Blood 65: 21-31, 1985.

15. Lange B, Valtieri M, Santoli D, Caracciolo D, Mavilio F, et al: Growth factor requirements of childhood acute leukemia: establishment of GM-CSF-dependent cell lines. Blood 70: 192-199, 1987.

16. Baersch G, Mollers T, Hotte A, Dockhorn-Dworniczak B, Rube C, et al: Good engraftment of B-cell precursor ALL in NOD-SCID mice. Klin Padiatr 209: 178-185, 1997.

17. Borgmann A, Baldy C, von Stackelberg A, Beyermann B, Fichtner I, et al: Childhood ALL blasts retain phenotypic and genotypic characteristics upon long-term serial passage in NOD/ SCID mice. Pediatr Hematol Oncol 17: 635-650, 2000.

18. Liem NLM, Papa RA, Milross CG, Schmid MA, Tajbakhsh M, et al: Characterization of childhood acute lymphoblastic leukemia xenograft models for the preclinical evaluation of new therapies. Blood 103: 3905-3914, 2004.

19. Lock RB, Liem N, Farnsworth ML, Milross CG, Xue C, et al: The nonobese diabetic/severe combined immunodeficient (NOD/SCID) mouse model of childhood acute lymphoblastic leukemia reveals intrinsic differences in biologic characteristics at diagnosis and relapse. Blood 99: 4100-4108, 2002.

20. Nijmeijer BA, Mollevanger P, van Zelderen-Bhola SL, KluinNelemans HC, Willemze R, et al: Monitoring of engraftment and progression of acute lymphoblastic leukemia in individual NOD/ SCID mice. Exp Hematol 29: 322-329, 2001.
21. Dörrie J, Gerauer H, Wachter Y and Zunino SJ: Resveratrol induces extensive apoptosis by depolarizing mitochondrial membranes and activating caspase-9 in acute lymphoblastic leukemia cells. Cancer Res 61: 4731-4739, 2001.

22. Dörrie J, Sapala K and Zunino SJ: Carnosol-induced apoptosis and downregulation of Bcl-2 in B-lineage leukemia cells. Cancer Lett 170: 33-39, 2001.

23. Kellner C and Zunino SJ: Nitric oxide is synthesized in acute leukemia cells after exposure to phenolic antioxidants and initially protects against mitochondrial membrane depolarization. Cancer Lett 215: 43-52, 2004.

24. Nachman JB, Sather HN, Sensel MG, Trigg ME, Cherlow JM, et al: Augmented post-induction therapy for children with highrisk acute lymphoblastic leukemia and a slow response to initial therapy. N Engl J Med 338: 1663-1671, 1998.

25. Crowell JA, Korytko PJ, Morrissey RL, Booth TD and Levine BS: Resveratrol-associated renal toxicity. Toxicol Sci 82: 614-619, 2004.

26. Zunino SJ, Storms DH and Ducore JM: Novel in vivo model of inducible multi-drug resistance in acute lymphoblastic leukemia with chromosomal translocation $\mathrm{t}(4 ; 11)$. Cancer Lett 296: 49-54, 2010.

27. Zunino SJ, Storms DH, Newman JW, Pedersen TL, Keen CL and Ducore JM: Resveratrol given intraperitoneally does not inhibit the growth of high-risk $t(4 ; 11)$ acute lymphoblastic leukemia cells in a NOD/SCID mouse model. Int J Oncol 40: 1277-1284, 2012.

28. Brown VA, Patel KR, Viskaduraki M, Crowell JA, Perloff M, et al: Repeat dose study of the cancer chemopreventive agent resveratrol in healthy volunteers: safety, pharmacokinetics, and effect on the insulin-like growth factor axis. Cancer Res 70: 9003-9011, 2010.

29. Patel KR, Scott E, Brown VA, Gescher AJ, Steward WP, et al: Clinical trials of resveratrol. Ann NY Acad Sci 1215: 161-169, 2011.

30. Walle T, Hsieh F, De Legge MH, Oatis JE and Walle UK: High absorption but very low bioavailability of oral resveratrol in humans. Drug Metab Dispos 32: 1377-1382, 2004.

31. Vitrac X, Desmouliere A, Brouillaud B, Krisa S, Deffieux G, et al: Distribution of [14C]-trans-resveratrol, a cancer chemopreventive polyphenol, in mouse tissues after oral administration. Life Sci 72: 2219-2233, 2003.

32. Wenzel E, Soldo T, Erbersdobler H and Somoza V: Bioactivity and metabolism of trans-resveratrol orally administered to Wistar rats. Mol Nutr Food Res 49: 482-494, 2005.

33. Baur JA and Sinclair DA: Therapeutic potential of resveratrol: the in vivo evidence. Nat Rev Drug Discov 5: 493-506, 2006.

34. Kimura Y and Okuda H: Resveratrol isolated from Polygonum cuspidatum root prevents tumor growth and metastasis to lung and tumor-induced neovascularization in Lewis lung carcinomabearing mice. J Nutr 131: 1844-1849, 2001.

35. Busquets S, Ametller E, Fuster G, Olivan M, Raab V, et al: Resveratrol, a natural diphenol, reduces metastatic growth in an experimental cancer model. Cancer Lett 245: 144-148, 2007.

36. Weng YL, Liao HF, Li AF, Chang JC and Chiou RY: Oral administration of resveratrol in suppression of pulmonary metastasis of BALB/c mice challenged with CT26 colorectal adenocarcinoma cells. Mol Nutr Food Res 54: 259-267, 2010.

37. Kweon SH, Song JH and Kim TS: Resveratrol-mediated reversal of doxorubicin resistance in acute myeloid leukemia cells via downregulation of MRP1 expression. Biochem Biophys Res Commun 395: 104-110, 2010.

38. Harikumar KB, Kunnumakkara1 AB, Sethi G, Diagaradjane P, Anand $\mathrm{P}$, et al: Resveratrol, a multitargeted agent, can enhance antitumor activity of gemcitabine in vitro and in orthotopic mouse model of human pancreatic cancer. Int J Cancer 127: 257-268, 2010 . 